\title{
A one year study on evaluation of pattern of caesarean section and its outcome before and after introduction of Janani Suraksha Yojna and maternal ambulances services
}

\author{
Alka Patel, Beenu Kushwah*, Anuradha Mishra \\ Department of Obstetrics and Gynaecology, Shyam Shah Medical College, Rewa, Madhya Pradesh, India \\ Received: 17 June 2016 \\ Accepted: 07 July 2016 \\ *Correspondence: \\ Dr. Beenu Kushwah, \\ E-mail: drbeenukushwah@gmail.com \\ Copyright: (C) the author(s), publisher and licensee Medip Academy. This is an open-access article distributed under \\ the terms of the Creative Commons Attribution Non-Commercial License, which permits unrestricted non-commercial \\ use, distribution, and reproduction in any medium, provided the original work is properly cited.
}

\begin{abstract}
Background: The steady rise in caesarean section rates is an emerging area of concern in mother-child healthcare and a matter of international attention. During last decade Janani Suraksha Program and maternal ambulances services have brought many significant changes in maternal and perinatal outcomes in India, one of which is significantly increased number of institutional deliveries, this may have brought a difference in pattern of cesarean sections as well. Present study has analyzed caesarean section trend before and after introduction of Janani Suraksha Yojna (JSY) and maternal ambulance services at our institute.

Methods: A structured proforma was filled up for every case and results were recorded on excel sheet. All the cases included in study were further divided in group 1 (deliveries done in year 2004-2005), group 2 (deliveries done in year 2014-2015) before and after introduction of JSY and maternal ambulance services respectively. Comparative analysis between study group1 and group 2 was done using Pearson Chi square test.

Results: In group1, total deliveries during study period were 6050, out of which $562(9.28 \%)$ were caesarean deliveries. In group 2, total deliveries was 8674 , out of which $1182(13.62 \%)$ were caesarean deliveries. The most common indication for which the rise in caesarean section rate is seen in our study was repeat caesarean section, in group 1 was $21.7 \%$ and in group 2 was $32.2 \%$, followed by failed medical induction.

Conclusions: The rate of caesarean section has increased after introduction of JSY and maternal ambulance services which may be a direct consequence of increase in institutional deliveries.
\end{abstract}

Keywords: JSY, Maternal ambulance services, Caesarean section incidence

\section{INTRODUCTION}

Caesarean section is the oldest of operations in surgery and was mainly meant to save the mother when a vaginal delivery was not possible even after a destructive procedure. One of the most controversial features of modern obstetric practice is the dramatic increase in the incidence of caesarean section. Data suggest at least a threefold increase from less than 5\% to more than $15 \%$ in the course of a single decade with a persistent upward trend. With increasing safe methods of anaesthesia, advent of antibiotics, blood transfusion facilities, use of lower segment incision, better understanding of fluid and electrolyte balance during labor and better surgical techniques, the indications for caesarean section are liberalized both in the interest of mother and fetus.

The steadily increasing global rate of caesarean section have become one of the most debated topics in maternity care as its prevalence has increased alarmingly in the last few years. ${ }^{1,2}$ Caesarean section rate in USA is $29.1 \%$, England $21.5 \% .^{3,4}$ 
There is no consensus about what the ideal caesarean section rate should be, however WHO states that no additional health benefits are associated with a caesarean section rate above $15 \% .^{5}$ However critical evaluation of the attitude towards the liberalization of the indications is needed. There is also need to explore alternative strategies which can help to achieve vaginal deliveries without unduly jeopardizing maternal and fetal wellbeing. Leitch stated that indications for caesarean section should be the focus of study that leads to increased caesarean section rate. ${ }^{6}$

In a developing country like India there is an increasing trend of C-section delivery with increase in the institutional deliveries and growing access to gynaecological and obstetric care. A study by Indian Council of Medical Research (ICMR) in 33 tertiary care institutions noted that the average caesarean section rate increased from 21.8 percent in 1993-1994 to 25.4 percent in 1998-1997. Studies also suggest that one of the important factors behind performance of C-section could be high education background of women, more presence of private hospitals or sometime interplay between doctors' motivation and financial incentives of the hospitals behind such trend.

Caesarean section like most other invasive procedures is principally intended to improve medical outcome. Because pregnancy outcomes relate to both mother and fetus, caesarean section can improve either maternal or fetal outcome or both. Caesarean delivery has many possible immediate untoward consequences too. There can be an increased risk for postpartum infectious morbidity despite antibiotic prophylaxis, an increased risk of significant blood loss and blood products replacement and an increased risk of anaesthetic complications. If proper decision is taken to select the cases for caesarean section, the number of primary sections could be brought down, as post caesarean pregnancies are high risk cases and need close supervision, scrupulous care evaluation.

During last decade Janani Suraksha Program and maternal ambulances services have brought many significant changes in maternal and perinatal outcomes in India, one of which is significantly increased number of institutional deliveries, this may have brought a difference in pattern of caesarean sections as well, analysis of which has not been incorporated in much of the studies.

Present study has been conducted in department of obstetrics and gynaecology, Shyam Shah Medical College, Rewa, MP, India to analyse the difference in pattern of caesarean sections before and after introduction of JSY and Maternal ambulances services over a period of one year.

\section{METHODS}

The present study entitled "a one year study on evaluation of pattern of caesarean section and its outcome before and after introduction of JSY and maternal ambulance services" was conducted in the department of obstetrics and gynaecology, Shyam Shah Medical College and Associated Gandhi Memorial Hospital, Rewa, Madhya Pradesh, India.

GMH is a government teaching institution which serves as a tertiary referral centre for a huge area including the districts Rewa, Sidhi, Singrouli and Satna. A team of obstetricians, anesthesiologists and neonatologists is available round the clock for managing emergencies. The hospital is equipped with operation theatres, blood bank and obstetrics and neonatal ICU.

\section{Methodology}

Data collection and analysis: A structured proforma was filled up for every case and results were recorded on excel sheet, which included information on age, gravidity, literacy, area of residence, type of antenatal care received, referral status, type of delivery, indication of LSCS, complication of LSCS, Neonatal outcome. Number of deliveries, total number of LSCS, grouping of indication of LSCS, TGCS groups, total admissions, live births, JSY beneficiaries, total neonatal admissions \& neonatal deaths were all recorded from departmental statistics records. All the cases included in study were further divided in group 1 and group 2 as following:

- Group 1: all the caesarean deliveries done in year 2004-2005.

(One year before the introduction of JSY and maternal ambulance services).

- Group 2: All the caesarean deliveries done in year 2014-2015.

After ten year of introduction of JSY and ambulances services when these services are well established.

\section{Inclusion criteria}

All the cases of caesarean delivery during study time were included.

\section{Exclusion criteria}

Clinically diagnosed cases of ruptured uterus and proven on laparotomy.

\section{Statistical analysis}

Comparative analysis between study group1 and group 2 was done using Pearson Chi square test. Differences with 
$\mathrm{p}$ values of less or equal to 0.05 was considered statistically significant.

\section{RESULTS}

As shown in Table 1, in group 1, total number of deliveries during the study period was 6050 , out of which $562(9.28 \%)$ was caesarean deliveries. In group 2 total number of deliveries during study period was 8674 , out of which $1182(13.62 \%)$ were caesarean deliveries. There is significant increase in total number of deliveries $(\mathrm{P}<0.001)$ and in caesarean section rate $(\mathrm{P}<0.001)$ between group 1 and 2 .

Table 1: Incidence of total deliveries and caesarean section.

\begin{tabular}{|llll|}
\hline Group & $\begin{array}{l}\text { Total } \\
\text { deliveries }\end{array}$ & $\begin{array}{l}\text { Total } \\
\text { caesarean }\end{array}$ & Percentage \\
\hline 1 & 6050 & 562 & $9.28 \%$ \\
\hline 2 & 8674 & 1182 & $13.62 \%$ \\
\hline
\end{tabular}

Table 2: Distribution of cases according to age.

\begin{tabular}{|c|c|c|c|c|c|c|c|}
\hline \multirow{2}{*}{ Group } & \multicolumn{2}{|c|}{$<18$ years } & \multicolumn{2}{|c|}{$\begin{array}{l}18-35 \\
\text { years }\end{array}$} & \multicolumn{2}{|c|}{ >35 years } & \multirow{2}{*}{ Total } \\
\hline & No & $\%$ & No & $\%$ & No & $\%$ & \\
\hline 1 & 90 & $16.01 \%$ & 466 & $82.9 \%$ & 12 & $1.07 \%$ & 562 \\
\hline 2 & 02 & $0.16 \%$ & 1168 & $98.8 \%$ & 12 & $1.01 \%$ & 1182 \\
\hline
\end{tabular}

As evident from Table 2, in group 1, out of 562; 90 $(16.01 \%)$ cases were less than 18 year of age, while in group 2 out of $1182 ; 2(0.16 \%)$ cases were less than 18 year of age. Total number of cases in less than 18 year of age decreased significantly $(\mathrm{P}<0001)$ over 10 years. There is no significant change in distribution of cases in age group of 18-35 year and >35 year.

Table 3: Distribution of cases according to parity.

\begin{tabular}{|l|lllll|}
\hline \multirow{2}{*}{ Group } & \multicolumn{2}{l}{ Nullipara } & \multicolumn{2}{l|}{ Multipara } & Total \\
& No & \% & No & \% & \\
\hline 1 & 293 & $52.14 \%$ & 269 & $47.86 \%$ & 562 \\
\hline 2 & 596 & $50.40 \%$ & 586 & $49.5 \%$ & 1182 \\
\hline
\end{tabular}

Table 3 compares parity between two groups, in group1, among 562 patients, $293(52.14 \%)$ were nulliparous while $269(47.86 \%)$ were multiparous. In group2, among 1182 patients $596(50.40 \%)$ were nulliparous while 586 (49.5\%) were multiparous. There is no significant change in parity between group 1 and group 2 .

It is evident from Figure 1 that in group 1, among 562 patients, $348(61.92 \%)$ belonged to rural area while only $214(38.0 \%)$ were from urban area. In group2, among 1182 patients, $933(78.9 \%)$ belonged to rural population while only $249(21.06 \%)$ were from urban population. There is significant increase $(\mathrm{P}<0.001)$ between the group1 and group2, regarding females coming from rural areas, indicating the positive effect of JSY and ambulances services in providing antenatal care to rural population.

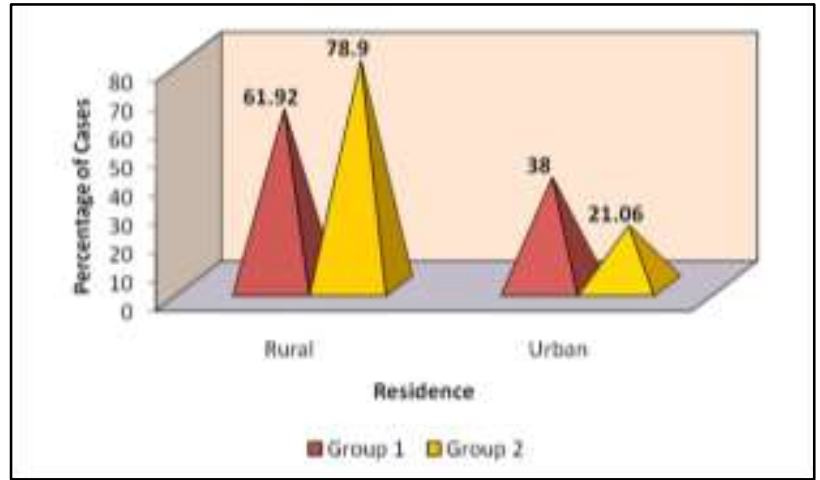

Figure 1: Distribution of cases according to residence.

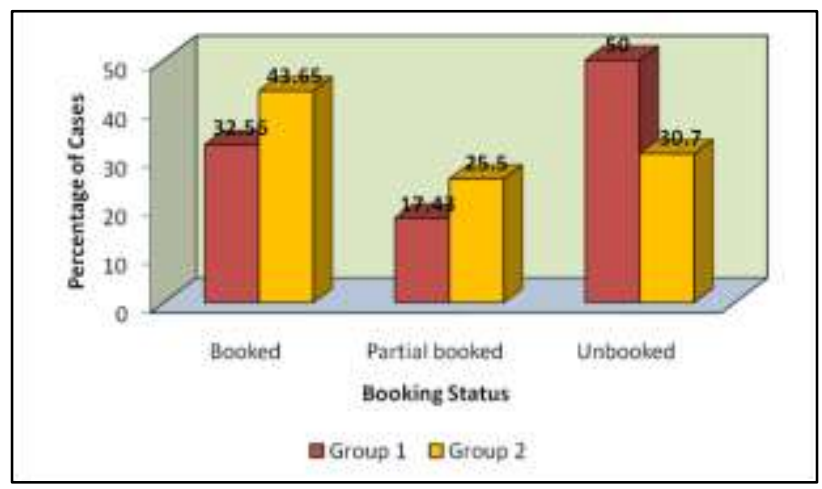

Figure 2: Distribution of cases according to booking status.

In group1, out of 562 patients $183(32.56 \%)$ were booked, $98(17.43 \%)$ were partially booked, $281(50 \%)$ were unbooked. In group 2, among 1182 patients 516 $(43.65 \%)$ were booked, $302(25.5 \%)$ were partially booked, $364(30.7 \%)$ were unbooked (Figure 2). There is significant difference in booking status between group1 and $2(\mathrm{p}<0.001)$.

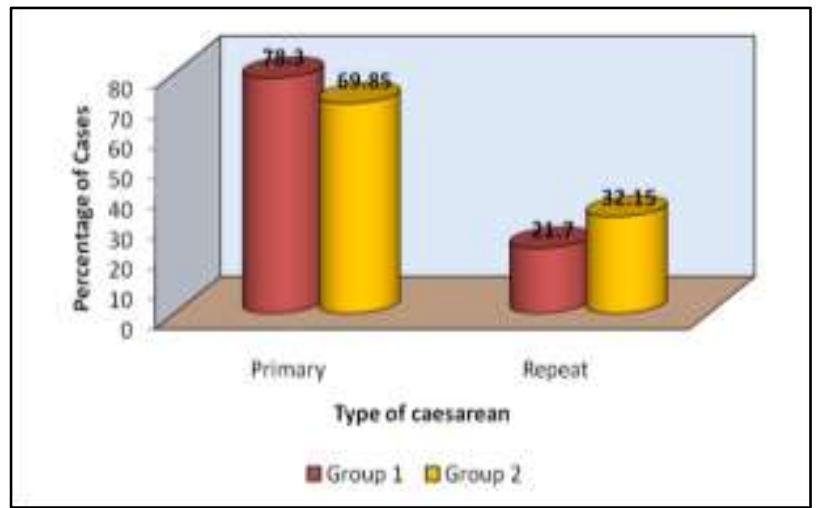

Figure 3: Distribution of cases according to type of caesarean. 
Figure 3 suggests that in group1, primary caesarean sections done were $440(78.3 \%)$ cases and repeat caesarean sections were $122(21.7 \%)$ cases. In group2 out of 1182 cases, $802(69.85 \%)$ were primary caesarean and $380(32.15 \%)$ were repeat caesarean section. There is significant increase in rate of repeat caesarean sections $(\mathrm{p}<0.001)$.

As it is evident from Figure 4 that in the group1, study fetal distress was the most common indication i.e.192 $(34.1 \%)$ cases followed by previous section $122(21.5 \%)$, CPD 121 (21.5\%), Breech 64 (11.3\%), PIH+preeclampsia $63(11.03 \%)$, PROM 49 (8\%), NPOL 29 (5.16\%), POP+DTA 29 (5.16\%). Malpresentation other than breech was $69(12.27 \%)$. While in group 2, previous section was the most common indication i.e. 380 $(32.15 \%)$ cases followed by fetal distress $329(27.85 \%)$, CPD 163 (13.79\%), failed induction 126 (10.65\%), PIH+pre-eclampsia 99 (8.38), breech 98 (8.29\%), NPOL 70 (5.92\%), oligohydramnios $60(5.08 \%)$, PROM 54 $(4.57 \%)$. Malpresentation other than breech were 103 $(8.71 \%)$

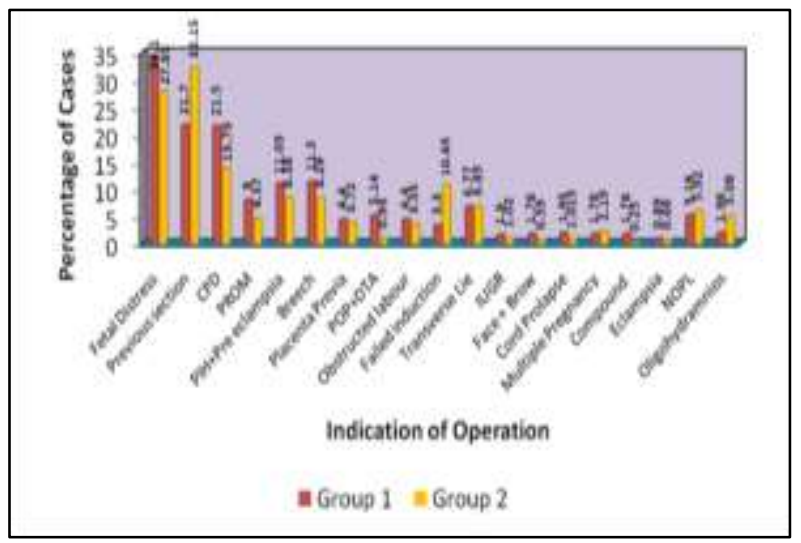

Figure 4: Distribution of cases according to indication of caesarean.

It is clear from Figure 4 that there is significant difference in distribution of cases among some indications between group 1 and group 2, previous section $(\mathrm{P}<0.0008)$, Failed medical induction $(\mathrm{P}<0.0001)$, CPD $(\mathrm{P}<0.0008)$, Foetal distress $\quad(\mathrm{P}<0.02), \quad \mathrm{POP}+\mathrm{DTA} \quad(\mathrm{P}<0.0001), \quad \mathrm{PROM}$ $(\mathrm{P}<0.0017)$, oligohydramnios $(\mathrm{p}<0.0025)$.

In group 1 atonic PPH occurred intra-operatively in 31 $(5.5 \%)$ of cases, extension of uterine incision occurred in $21(3.7 \%)$ of cases, adhesion was present in $30(5.3 \%)$ of cases. Bladder injury occurred in $1(0.18 \%)$ case. Blood transfusion was done in $6(1.07 \%)$ of cases. Anaesthetic complications occurred in $11(1.18 \%)$ of cases. Cardiac arrest occurred in $1(0.17 \%)$ case. In group 2 atonic PPH occurred intra-operatively in $23(1.95 \%)$ of cases. Extension of uterine incision occurred in $13(1.09 \%)$ of cases. Previous adhesion found in $77(6.51 \%)$ of cases. Blood transfusion was done in $17(1.43 \%)$ of cases. Anaesthetic complication occurred in 34 (2.88\%) of cases (Figure 5).

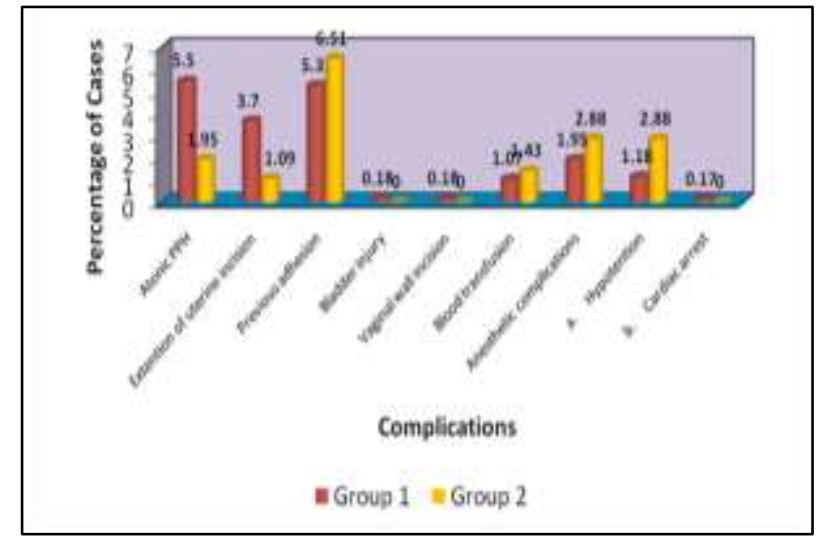

Figure 5: Distribution of per-operative complications across both the groups.

It is evident from Figure 6 that in group 1, postoperative wound sepsis seen in $79(14.05 \%)$ of cases, of which in $11(1.95 \%)$ of cases restoring done. Febrile morbidity occurred in $78(13.8 \%)$ of cases, followed by UTI 30 (5.3\%), BT 16 (2.85\%). There were $2(0.35 \%)$ postoperative mortality due to thromboembolism. In group 2, wound sepsis occurred in 90 (7.61\%) of cases, of which $66(5.58 \%)$ needed restoring. Blood transfusion was done in $46(3.89 \%)$ of cases. Febrile morbidity occurred in $36(3.04 \%)$ of cases.

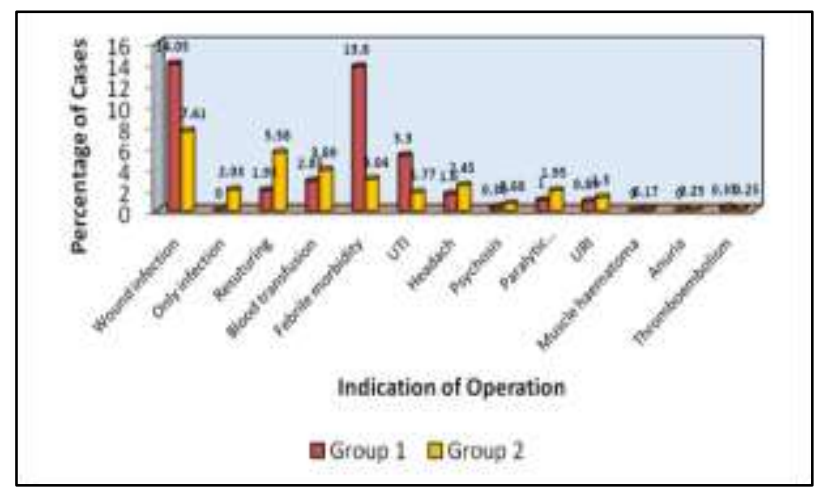

Figure 6: Distribution of cases according to postoperative complications.

There were $2(0.17 \%)$ cases of muscle haematoma postoperatively; exploratory laparotomy was done to drain out haematoma in both cases. there were $3(0.25 \%)$ cases that developed Anuria postoperatively. There were 3 $(0.25 \%)$ post-operative mortality due to thromboembolism. It is clear that there is significant decrease in wound sepsis in group 2 as compare to group 1 , and rate of restoring increased in group 2 .

\section{DISCUSSION}

The present study is a prospective and retrospective hospital record based study, carried out at the department of obstetrics and gynaecology at Shyam Shah Medical College and associated Gandhi Memorial Hospital, Rewa, 
to assess pattern of caesarean section and its outcome before and after introduction of JSY and maternal ambulance services. Results of present study were analyzed, and compared with the other studies conducted before.

\section{Socio Demographic characteristics of study population}

\section{Age}

Maximum number of caesarean sections in group1 and group 2 were in age group of 18 to 35 years of age which was $83 \%$ and $98 \%$ respectively, which is comparable with the Naidu P, Chakravarty, Kumar A, Soin U, and Unnikrishnan B et al study done in South coastal India. ${ }^{8-}$

${ }^{12}$ It also reflects the maximum fertile period of women's life and common child bearing age group.

There is significant decrease in number of patients in less than 18 years of age between group 1 and group 2 which could be an indirect effect of improved awareness regarding ill effects of underage pregnancy.

\section{Parity}

The maximum numbers of caesarean cases were observed in primiparous women in both the groups $(52.1 \%, 50.4 \%$ respectively) which are comparable to study done by Kumar A at Shimla, and Soin et al. ${ }^{10,11}$ In a study by Unnikrishnan B et al, $47.8 \%$ cases were primiparous and $46.6 \%$ were multiparous which is comparable to present study. ${ }^{12}$

\section{Residence}

In both the group rural population is main contributor $(62 \%, 79 \%$ respectively) but has increased significantly over last decade which can be correlated with the improved maternal transport facility across the Rewa division.

\section{Booking status}

Maximum number of cases in both group belonged to partially booked + unbooked status $(67.4 \%, 56.2 \%$ respectively) which is comparable with study done by Subedi $\mathrm{S}$ where $98 \%$ cases were unbooked or partially booked. ${ }^{13}$ In a study done by Haider $\mathrm{G}$ et al done in Hyderabad Sindh, 56\% cases were unbooked, Hafeeze M et al reported $61.38 \%$ unbooked cases while in study done by Unnikrishnan B et al, $87.5 \%$ case were booked which could be reflection of overall better health indicators in South Indian States in our country. ${ }^{12,14,15}$

\section{Type and incidence of caesarean section}

In present study majority of the caesarean sections in group $1(82.39 \%)$ were emergency compared with only $17.6 \%$ of elective Caesarean delivery, in group $2(71.6 \%)$ were emergency and $28.4 \%$ were elective, Mutihir et al reported similar findings. ${ }^{16}$ This high rate of emergency Caesarean section could be attributed to the fact that these are tertiary health facilities which serve as referral centers where complicated labors could be managed more effectively. In most cases, the lifesaving CS remains the only choice. ${ }^{17}$ Another possibility is the dearth of expertise at secondary health facilities in these regions. Therefore, experts that could manage complicated labour are only available at the tertiary health facilities. Increase in number of emergency caesarean rate in present study is a direct result of 24 hours availability of maternal ambulances services across the region which could transfer the patients to our institute whenever emergency arose at peripheral centers.

During the study period in group 1 there were 6050 deliveries out of which 562 were delivered by caesarean section (9.3\%), in group 2 there were 8674 deliveries out of which 1182 were delivered by caesarean section $(13.6 \%)$. There is significant increase in incidence of caesarean section in group 2 as compared to group 1 . This rise in caesarean section rate is comparable with B Unnikrishnan et al (23.27\%), Shanti Set al (19.9\%), Sobande A et al (21.1\%), while Gulfareen $\mathrm{H}$ et al found $64.7 \%$ caesarean rate in their study done in Hyderabad, Sindh Pakistan in a tertiary care hospital. ${ }^{12,13,17,18}$ Increase in caesarean section rates may be a direct effect of universal coverage of JSY services and round the clock availability of maternal ambulance services but other causes should also be taken care of and be analyzed as we did in present study and is discussed here in detail.

According to Ratnam, the rising trend in caesarean section rates is not only limited to the developed countries but also includes several developing countries, there is almost $1 \%$ rise per year in the caesarean rate in the USA/Canada compared to an increase of $0.5-0.75 \%$ per year in some of the countries in developing world. ${ }^{19}$

\section{Indications of caesarean section}

The most common indication for which the rise in caesarean section rate seen in our study was" repeat caesarean section', in group 1was $21.7 \%$ and in group 2 it was $32.2 \%$. Lubna Ali from Karachi Pakistan reported repeat caesarean section the commonest indication for caesarean section, similar trends have been found in Northern Greece $(30.9 \%)$ by Mersaovdi et al. ${ }^{20,21}$ So the decision for primary caesarean section is important unless there is a clear, compelling and well supported justification for caesarean section, a carefully supervised justified trial of labour is necessary. ${ }^{22,23}$ Trial of scar in singleton pregnancies can be given to reduce the rate of repeated caesarean section as the risk of uterine rupture is low $0.3 \% .^{24}$ Successful vaginal birth after caesarean (VBAC) in grand multiparous does not lead to increased maternal complication. ${ }^{25}$ Increase in institutional deliveries because of JSY and maternal transport facilities, is a direct cause of increase in primary caesarean rates resulting in more and more repeat 
caesareans sections because of a generalized low threshold for the trial of labour in these patients for the fear of scar rupture and its ill consequences.

For women who have had a previous CS, a movement to prevent repeats CS was largely driven by mothers supporting vaginal birth after Caesarean section. They helped to influence change in standard medical practice, and rates of VBAC rose in the 1980s and early $1990 \mathrm{~s} .{ }^{26} \mathrm{~A}$ major turning point occurred in 1996 when a wellpublicized Nova Scotia study reported that vaginal delivery after previous CS resulted in more maternal complications than did repeat $\mathrm{CS} .{ }^{27}$ Subsequent logistical and liability concerns led many hospitals to enact overt or de facto bans of VBAC. ${ }^{28}$ As a result, the rate at which VBAC was attempted fell from $28.3 \%$ in 1996 to less than $10 \%$ in $2010 .^{26-28}$ There were controversial findings on the risks and benefits of trial of labour and elective repeat $\mathrm{CS}$, and little or no evidence on short- or long-term neonatal outcomes after trial of labour compared to elective repeat $\mathrm{CS}^{29}$ Notwithstanding, enhanced access to VBAC has been recommended based on current findings on the safety of VBAC compared to repeat CS, indicating that $60 \%$ to $80 \%$ of women can achieve a safe vaginal delivery after a previous lower uterine segment $\mathrm{CS}^{30,31} \mathrm{~A}$ similar recommendation also emerged from the National Institutes of Health VBAC conference panel in March $2010 .^{29}$ It must be noted that a study published in 2012 that used a restricted patient preference cohort design demonstrated that planned elective repeat CS in women with one prior CS was associated with lower fetal risk and lower rates of infant death or critical outcome than planned VBAC however, the possibility that confounding by indication influenced the outcome of this study cannot be ruled out. ${ }^{33}$ Ultimately, due to the decline in attempted VBACs and concerns from hospitals and care providers about VBAC safety, a quick reduction in the rate of elective repeat CS is unlikely. In present study no case of previous caesarean has been medically induced as this is a general guideline that we are following, while evidences are there, which are favoring induction in previous section cases if properly selected. ${ }^{33-35}$ Therefore institutional protocol for managing these pregnancies more appropriately is required in terms of performing elective inductions in those patients who follow a certain set of criteria.

Second most common indication for which there is rise in caesarean section rate seen in present study was' Failed Medical Induction'. In group 1 percentage of caesarean section for failed medical induction were $3.3 \%$ while in group 2 it was $10.65 \%$, this is comparable to study done by Arulkumaran et al $(16.5 \%)$ Unnikrishnan B et al. $(8.8 \%) .{ }^{12,19}$ Dunne $\mathrm{C}$ et al found that elective induction leads to more unplanned caesarean section in nulliparous women and to increased postpartum complication for both nulliparous and multiparous women. ${ }^{36}$

The significant increase in caesarean section rate for failed medical induction in group 2 as compare to group 1 could be due to increased number of planned inductions. There are increasing number of patient who report to our hospital at 40 weeks plus gestation if they don't go in spontaneous labour and as per our hospital protocol these patients are taken up for planned medical induction before 41 weeks. Earlier due to lack of awareness and maternal transport services patients used to remain at home waiting for spontaneous labour but now they come to hospital and get medically induced if fulfilled criteria for induction.

Third most common indication for which there has been a rise in caesarean section rate seen in our study was 'olighohydramnios' in group 1, severe oligohydramnios as indication for caesarean section was $1.9 \%$ while in group 2 it was $5 \%$, this is comparable to study done by Jasia J et al (4.68\%\%), Subhashini R et al $(8.52 \%)$ and Fatima $\mathrm{R}$ et al 9.5\%). ${ }^{37-39}$ This significant difference between group1 and group 2 could be due increased detection rates of oligohydramnios as a result of better Antenatal care and maternal transport services.

The incidence of Obstructed labour and DTA cases decreased significantly in study group $2(4.48 \%)$ as compare to study group $1(9.54 \%)$. This is comparable to study done by Haider $\mathrm{G}$ et al $(6.5 \%) .{ }^{14}$ Shanti subedi reported $1.5 \%$ cases of obstructed labour while Unnikrishnan B et al reported only $0.5 \%$ cases of obstructed labour in their study which denotes better antenatal care and transport services in south India. ${ }^{12,13}$ The significant decrease in incidence of obstructed labour and DTA cases in group 2 could be a direct positive effect of JSY and maternal ambulance services by which patients are transported to tertiary care centre earlier before they go to obstruction and DTA.

\section{Complications of caesarean section}

\section{Per-operative complication}

In group 1 Intra-operative atonic $\mathrm{PPH}$ was the most common complication observed followed by previous adhesion (5\%), extension of uterine incision (3.7\%), in group 2 there was marked decrease in number of atonic $\mathrm{PPH}(1.95 \%)$ as compared to group1, there were only $1.1 \%$ cases had extension of uterine incision in group 2, this may be a general effect of improved skills in managing these cases. $6.5 \%$ cases had adhesions in group 2 which is due to increase rate of repeat caesarean sections rate. Intra-operative blood transfusion increased in group $2(1.86 \%)$ as compare to group $1(1 \%)$, which could be due to betterment of Blood bank facilities in our hospital but may also be due to the fact that because of ambulances services more and more complicated and underprivileged pregnant females are being brought to the hospitals now and being effectively managed. 


\section{Post-operative complication}

In group 1 wound infection was the most common (14\%) postoperative complication, out of which only $1.9 \%$ needed restoring, this was followed by febrile morbidity $(13.8 \%)$, UTI (5.3\%), blood transfusion (2.85\%), paralytic ileus $(1 \%)$. In group 2 also the most common postoperative complication was wound infection $(7.6 \%)$, out of which $5.6 \%$ cases needed restoring, second most common postoperative complication in group 2 were febrile morbidity $(7 \%)$ followed by Blood transfusion $(4 \%)$. This is comparable with the study done by Ugawu EOV et al and Sobade AA et al. ${ }^{18,40}$ There has been significant decrease in wound infection rate in group 2 as compared to group lindicating betterment of maternal intraoperative and postoperative care.

\section{CONCLUSION}

A significant rise in institutional and C-section delivery is found between 1992-93 (NFHS-1) and 2007-08 (DLHS3 ) in most of the states in India. The scheme like Janani Suraksha Yajona (JSY) may have a great impact on accepting institutional deliveries by poor women. Rising institutional delivery may be a reason of the increase of $\mathrm{CS}$ in India. An increase in the rates of caesarean section delivery is a burden on health system. Unnecessary caesarean delivery also put strain on family and may complicate maternal and child health. Therefore, the decision to perform a C-section delivery must be chosen carefully and should not be overshadowed by other unreasonable factors. Utilization of ANC, better doctor patient communication, doctor's commitment to reduce the rate of CS, government's intention to develop better health care infrastructure may help to reduce the high and increasing rate of caesarean delivery in this era of high institutional deliveries because of more \& more utilization of JSY and Maternal ambulances services.

Funding: No funding sources

Conflict of interest: None declared

Ethical approval: The study was approved by the Institutional Ethics Committee

\section{REFERENCES}

1. Tampakoudis P, Assimakopoulos E, Grimbizis G, Zafrakas M, Tampakoudis G, Mantalenakis S, et al. Caesarean section rates and indications in Greece: data from 24 year period in a teaching hospital. ClinExpObstetGynecol. 2004;31:289-92.

2. Lee SI, Khang YH, Lee MS. Women's attitudes towards mode of delivery in a society with high caesarean section rates. Birth. 2004;31:108-16.

3. Hamilton BE, Ventura SJ, Martin JA, Sulton PD. Preliminary births for 2004. Health E-Stats. 2005(15). Available at http://www.cdc.gov/nchs/data/hestat/prelimbirths04/ prelimbirths04health.htm.
4. Thomas J, Paranjothy S. The national sentinel caesarean section audit report. RCOG press, 2001. Available https://www.rcog.org.uk/globalassets/documents/gui delines/research--audit/nscs_audit.pdf.

5. Belizan JM, Althabe F, Barros FC, Alexander S. Rates and implications of caesarean sections in Latin America. BMJ. 1999;319:1397-402.

6. Leitch CR, Walkers JJ. Caesarean section rates. BMJ. 1994;308:133-4.

7. Kambo I, Bedi N, Dhillon BS, Saxena N. A critical appraisal of cesarean section rates at teaching hospitals in India. Int $\mathrm{J}$ Gynaecol Obstet. 2002;79(2):151-8.

8. Naidu PNJ. Obset Gynecol India. 1962;12:549.

9. Chakravarty J. Obset Gynecol India. 1971:21.

10. Kumar A, Thakur S. Maternal complications in caesarean section deliveries. J Obstet Gynecol India. 1996;20:36-40.

11. Usha S. A clinical study of caesarean section, 1980.

12. Unnikrishnan B, Rakshith $P$, Aishwarya A, Nithin K, Rekha T, Prasanna P, et al. Trends and indications for caesarean section in a tertiary care obstetric hospital in coastal South India. AMJ. 2010;3(12):821-5.

13. Geidam AD, Audu BM, Kawuwa BM, Obed TY. Rising trend and indications of caesarean section at the university of Maiduguri Teaching Hospital, Nigeria. Ann Afr Med. 2009;8:127-32.

14. Subedi S. Rising rate of cesarean section- a year review. Journal of Nobel Medical College. 2012;1(2):72-6.

15. Haider G, Zehra N, Munir AA, Haider A. Frequency and indication of caesarean section in a tertiary care hospital. Pak J Med Sci. 2009;25(5):791-6.

16. Hafeez M, Yasin A, Badar N, Pasha MI, Akram N, Gulzar B. Prevalence and indication of caesarean section in a teaching hospital. JIMSA. 2014;27(1):15-6.

17. Mutihir JT, Daru PH, Ujah IAO. Elective caesarean sections at the Jos university teaching hospital. Trop J ObstetGynecol. 2005;22(1):39-41.

18. Sobade AA, Archibong EI, Eskander M. Primary caesarean section in nulliparous and grand multiparous Saudi women from Abharegion: indication and outcome. WATAM. 2003;22(3):2325.

19. Rao B, Ratnam SS, Kumaran A. Changing tends in caesarean section. Obst And Gynae for Postgraduates. 1999;1:145.

20. Ali L, Tayyab S, Parveen F. Caesarean c-section rate, current trends. J Surg Pak. 2007;12(2):64-6.

21. Dinas K, Mavromatidis G, Dovas D, Giannoulis C, Tantanasis T, Loufopoulos A, et al. Current caesarean section delivery rates and indications in a major public hospital in Northern Greece. Aust N Z J Obstet Gynaecol. 2008;48(2):142-6.

22. Ali L, Tayyab S. Caesarean section rate, curremt trends. J Surg Pakistan. 2007;1:62-6. 
23. Choudhary SM, Ayaz A. Efforts to reduce caesarean section Rate. J Surg Pakistan. 2003;8(1):25-30.

24. Spong CY, Lanndon MB. Risk of uterine rupture and adverse perinatal outcome at term after caesarean delivery. ObstetGynaecol. 2007;110(4):801-7.

25. Kugler E, Shoham-Vardi I. The safety of a trial of Labour after caesarean section in a grand multiparous population. Arch Gynaecol Obstet. 2008;277:339-49.

26. Gregory KD, Fridman M, Korst L. Trends and patterns of vaginal birth after cesarean availability in the United States. Semin Perinatol. 2010;34(4):23743.

27. McMahon MJ, Luther ER, Bowes WA, Olshan AF. Comparison of a trial of labor with an elective second caesarean section. $\mathrm{N}$ Engl $\mathrm{J}$ Med. 1996;335:689-95.

28. Cunningham FG, Bangdiwala S, Brown SS, Dean TM, Frederiksen M, Hogue CJ, et al. National institutes of health consensus development conference statement: vaginal birth after cesarean: New Insights. March 8-10, 2010. Obstet Gynecol. 2010;115:1279-95.

29. National Center for Health Statistics. Health indicators, 2012. Available at http://www.healthindicators.gov/Indicators/Priorcesa reanbirths_1134/Profile/Data. Accessed on 26 July 2012.

30. Grady D. New guidelines seek to reduce repeat Caesareans. The New York Times, 2010. Available at http://www.nytimes.com /2010/07/22/health/22birth.html. Accessed on 26 July 2012.

31. Health in the News. New cesarean guidelines: will they really reduce the rate of repeat C-sections?
Available at http://www.everydayhealth.com /blog/health-in-the-news/2010/07/23/new-cesareanguidelines. Accessed on 26 July 2012.

32. Crowther CA, Dodd JM, Hiller JE, Haslam RR, Robinson JS. Birth after caesarean study group. Planned vaginal birth or elective repeat caesarean: patient preference restricted cohort with nested randomised trial. PLoS Med. 2012;9(3):e1001192.

33. Sims EJ, Newman RB, Husley TC. Vaginal birth after caesarean: to induce or not to induce. Am J Obstet Gynecol. 2001;184(6):1122-4.

34. Sanchez-Ramos L, Gaudier FL, Kaunitz AM. Cervical ripening and labour induction after previous caesarean delivery. Clin Obstet Gynecol. 2000;43:513-23.

35. Delancy T, Young DC. Spontaneous versus induced labour after a previous caesarean delivery. Obstet Gynecol. 2003;102;39-44.

36. Dunne C, Dasilva O, Schmidta G, Natale R. J Obstet Gynecol. 2009;31(12):1124-30.

37. Jasia J, Mansoor MH, Mansoor A. Analysis of caesarean sections. Journal of Rawalpindi Medical College (JRMC). 2013;17(1):101-3.

38. Subhashini R, Uma N. Changing in caesarean delivery. IAIM. 2015;2(3):96-102.

39. Rahman F, Haque J, Bashir SJ, Bashar A. Trend of caesarean section in a tertiary level of hospital in Bangladesh in one year period, 2015. Available at https://www.researchgate.net/publication/283016574 _trends_of_caesarean_section_in_a_tertiary_level_h ospital_in_bangladesh_in_1_year_period.

40. Ugawu EOV, Eobioha KC, Okezie OA, Gwu AOU. A five year survey of caesarean delivery at a Nigerian Tertiary Hospital. Ann Med Health Sci Res. 2011;1(1);77-83.

Cite this article as: Patel A, Kushwah B, Mishra A. A one year study on evaluation of pattern of caesarean section and its outcome before and after introduction of Janani Suraksha Yojna and maternal ambulances services. Int J Reprod Contracept Obstet Gynecol 2016;5:2744-51. 